\title{
The cost-effectiveness of an early interventional strategy in non-ST-elevation acute coronary syndrome based on the RITA 3 trial
}

\author{
M Henriksson, ${ }^{1,2}$ D M Epstein, ${ }^{1}$ S J Palmer, ${ }^{1}$ M J Sculpher, ${ }^{1}$ T C Clayton, ${ }^{3}$ S J Pocock, ${ }^{3}$ \\ $\mathrm{R}$ A Henderson, ${ }^{4} \mathrm{M} \mathrm{J}$ Buxton, ${ }^{5} \mathrm{~K}$ A A Fox ${ }^{6}$
}

\begin{abstract}
- Additional report is published online only at http://heart.bmj. com/content/vol94/issue6

${ }^{1}$ Centre for Health Economics, University of York, UK; ${ }^{2}$ Center for Medical Technology Assessment, Linköping University, Sweden; ${ }^{3}$ Medical Statistics Unit, London School of Hygiene and Tropical Medicine, London, UK: ${ }^{4}$ Nottingham City Hospital NHS Trust, Nottingham UK: ${ }^{5}$ Health Economics Research Group, Brunel University, Uxbridge, UK:

${ }^{6}$ Centre for Cardiovascular Science, Department of Medical and Radiological Sciences, University of Edinburgh, UK
\end{abstract}

Correspondence to: Martin Henriksson, Center for Medical Technology Assessment, Linköping University, 58183 Linköping, Sweden; martin.henriksson@ ihs.liu.se

Accepted 16 October 2007 Published Online First 21 November 2007

\section{ABSTRACT}

Background: Evidence suggests that an early interventional strategy for patients with non-ST-elevation acute coronary syndrome (NSTE-ACS) can improve health outcomes but also increase costs when compared with a conservative strategy.

Objective: The aim of this study was to assess the costeffectiveness of an early interventional strategy in different risk groups from a UK health-service perspective. Design: Decision-analytic model based on randomised clinical trial data.

Main outcome measures: Costs in UK Sterling at 2003/ 2004 prices and quality-adjusted life years (QALYs) combined into an incremental cost-effectiveness ratio. Methods: Data from the third Randomised Intervention Trial of unstable Angina (RITA 3) was employed to estimate rates of cardiovascular death and myocardial infarction, costs and health-related quality of life. Costeffectiveness was estimated over patients' lifetimes within the decision-analytic model.

Results: The mean incremental cost per QALY gained for an early interventional strategy was approximately $£ 55000, £ 22000$ and $£ 12000$ for patients at low, intermediate and high risk, respectively. The early interventional strategy is approximately $1 \%, 35 \%$ and $95 \%$ likely to be cost-effective for patients at low, intermediate and high risk, respectively, at a threshold of $£ 20000$ per QALY. The cost-effectiveness of early intervention in lowrisk patients is sensitive to assumptions about the duration of the treatment effect.

Conclusion: An early interventional strategy in patients presenting with NSTE-ACS is likely to be considered costeffective for patients at high and intermediate risk, but this is less likely to be the case for patients at low risk.

Non-ST-elevation acute coronary syndrome (NSTE-ACS) represents a major health burden to health care systems and patients face a substantial risk of mortality and cardiovascular events. Although evidence suggests that the use of a strategy of early angiography with a view to revascularisation in the management of patients with NSTE-ACS is associated with an increased risk of myocardial infarction (MI) or death during the index hospitalisation, the reduced risk subsequently implies an overall reduction in the risk of MI or death. ${ }^{1}$ The 5-year follow-up of the third Randomised Intervention Trial of unstable Angina (RITA 3) confirmed these findings, showing that an early interventional strategy reduced the risk of the composite endpoint of death or MI (odds ratio $0.78,95 \%$ CI 0.61 to 0.99$).{ }^{2}$ Furthermore, it has been shown that an early interventional strategy improves health-related quality of life at 1 year but also leads to increased costs when compared with a conservative strategy. ${ }^{3}$ In order to establish whether an early interventional strategy should be recommended for widespread implementation, its cost-effectiveness needs to be assessed to determine whether the gain in health outcomes justifies any increased costs.

Based on data from RITA 3, rates of cardiovascular death or MI, costs and health-related quality of life were estimated and extrapolated to the relevant lifetime time horizon within a decisionanalytic model. Since baseline risk is a potentially important predictor of both cardiovascular events and the effectiveness of early intervention, the model investigated cost-effectiveness in patients with different risk profiles at randomisation. ${ }^{2}$ Secondary analyses considered whether cost-effectiveness results changed when clinical results from a meta-analysis of trials were used in the model and when treatment effect was allowed to vary with baseline risk.

\section{METHODS}

\section{Overview}

The decision problem under investigation concerns whether an early interventional (routine angiography followed by revascularisation if clinically indicated) or a conservative strategy (ischaemia or symptom-driven angiography) should be recommended for patients presenting with NSTE-ACS. The analysis was undertaken from a UK healthservice perspective and costs expressed in UK Sterling (GBP) at 2003/2004 prices. Health outcomes were estimated in terms of quality-adjusted life years (OALYs). Costs and OALYs were discounted by $3.5 \%$ per annum. ${ }^{4}$

Lifetime mean costs and OALYs per patient for each strategy were estimated using a decisionanalytic model. The model comprised two stages: (i) a short-term decision tree representing the index hospitalisation period and (ii) a long-term Markov structure characterising the post-index period as shown in fig 1. Costs and OALYs were assigned to the outcomes of the index hospitalisation (no event, myocardial infarction or death) and for each year that the patient spends in each state in the long-term Markov structure. Comprehensive details of the statistical analyses and modelling methods are available in a technical report. (See supplementary report.) 
Figure 1 Model structure. CV, cardiovascular; CVD, cardiovascular death; Ml, myocardial infarction.

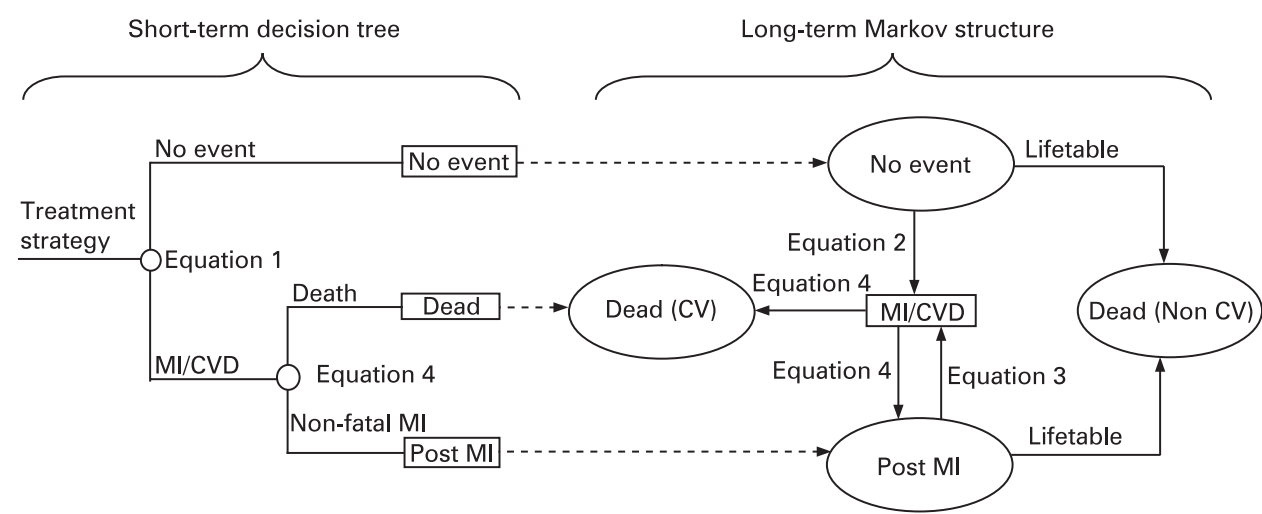

\section{Data sources}

Rates of cardiovascular death or MI, costs and health-related quality of life were estimated from individual-patient data from RITA 3 with additional information on non-cardiovascular mortality rates and the effectiveness of early intervention being incorporated from standard life-tables and meta-analyses of published trials, respectively.

The RITA 3 trial has been described elsewhere. ${ }^{25}$ Briefly, RITA 3 was a prospective, randomised multicentre trial with parallel groups, enrolling 1810 patients from 45 hospitals in England and Scotland, UK. Eligible patients had an episode of cardiac pain associated with electrocardiographic or previous arteriographic evidence of coronary artery disease, or an elevated serum cardiac marker, and were randomised to either an early interventional strategy or a conservative strategy. Patients in both treatment arms received optimal medical management. In the early interventional strategy, the aim was to also undertake coronary arteriography within $72 \mathrm{~h}$, with subsequent management guided by the angiographic findings. ${ }^{2}$

\section{Clinical effectiveness}

All statistical analyses included previously identified baseline risk factors for cardiac events and randomised treatment as separate covariates. ${ }^{2}$ The general approach was to drop nonsignificant covariates at the $5 \%$ level using a stepwise backward selection procedure. Covariates of structural importance, such as the treatment covariate in the estimation of event rates, were retained regardless of statistical significance.

The risk of the combined endpoint of cardiovascular death or MI during the index hospitalisation (defined as the time from randomisation to hospital discharge) was estimated using logistic regression. In fig 1 , this regression is represented as equation 1 and shows how the estimated risk is incorporated within the cost-effectiveness model. To estimate the risk of a composite endpoint during the remainder of the trial period (hospital discharge to end of follow-up), a time-to-event Weibull proportional hazards model was employed (equation 2). ${ }^{6}$ The estimated hazard was extrapolated beyond the period of trial follow-up, updating the age coefficient to account for the fact that this risk increases as patients age. A conservative assumption of no continued treatment effect from the early interventional strategy beyond 5 years was made. Alternative assumptions concerning the duration of the treatment effect after the 5 years of trial follow-up were investigated in separate scenarios.

There were insufficient patients in RITA 3 to estimate prognosis following a non-fatal MI (equation 3). Instead, the estimated risks of a first composite endpoint were used, adjusted with the proportionate risk for patients who had a non-fatal MI prior to their entry into the RITA 3. A conservative assumption was made that the early interventional strategy would not alter this particular risk

A separate logistic regression was used to estimate the proportion of composite endpoints being fatal or not (equation 4). Since this equation was applied to the risk of composite events at different stages of the model (the index and post-index periods), a dummy variable was used to investigate whether this proportion was different between these periods. The mortality risk from non-cardiovascular causes was estimated using UK sex and age-specific life-tables adjusted to exclude cardiovascular mortality. ${ }^{78}$

\section{Costs}

Comprehensive resource use data were collected for patients in RITA 3 up to 1-year follow-up and have been reported in detail elsewhere. ${ }^{9}$ Mean costs were estimated, differentiating between management strategies, for patients with and without a composite endpoint of cardiovascular death or MI, using standard OLS regression. Beyond 1 year, the analysis assumed no difference in costs between the treatment strategies in those patients not experiencing the composite event.

\section{Health-related quality of life}

Health-related quality-of-life (HROoL) data were collected in patients in RITA 3 at randomisation, 4 months, 1 year, and yearly thereafter using the EQ-5D instrument. Methods and results have been reported elsewhere. ${ }^{3}$ To estimate OALYs for each treatment strategy, the patients' time in each health state was multiplied by quality-adjustment weights (utilities), on a scale where 0 represents death and 1 represents full health, which are generated from the EQ-5D instrument based on the preferences of the UK general population. ${ }^{10}{ }^{11}$ Mean HRQoL of patients with different risk profiles at randomisation, and changes in HRQoL after randomisation, differentiating between the two management strategies and whether an infarction had occurred, were estimated using regression techniques. No difference in HRQoL between the treatment strategies was assumed after the first year in patients not experiencing a cardiac event. The long-term loss of HROoL in patients who survived an MI was assumed equivalent to the average difference in HRQoL of patients with and without past history of MI observed in the trial.

\section{Analysis}

The expected costs and OALYs of both strategies were combined into an incremental cost-effectiveness ratio (ICER), 
which should be interpreted as the additional cost of generating an additional OALY. ${ }^{12}$ Many health-care systems will compare the ICER with a threshold value to establish whether the strategy should, in principle, be recommended for implementation. ${ }^{13}$ The National Institute for Health and Clinical Excellence in the UK uses a threshold of around $£ 20000-£ 30000$ per OALY gained. ${ }^{4}$

Uncertainty in cost-effectiveness was evaluated using probabilistic sensitivity analysis where inputs into the analysis are defined as probability distributions which reflect the precision with which they are estimated. ${ }^{14}$ To investigate potential differences in costs and OALYs in patients with different risk profiles, the cost-effectiveness of an early interventional strategy was estimated using the individual covariate patterns of each patient in RITA 3. These are presented as a distribution of mean cost-effectiveness across the sample of trial patients. More detailed estimates are then presented for a series of illustrative patients within the overall sample. In RITA 3, a multivariate predictive model for death or MI within 5 years was used to calculate a risk score defining quartiles of risk (risk groups 1 to 4). ${ }^{2}$ Because of the much higher event rate in the top quartile, this quartile was then further subdivided into equalsized top two-eighths of risk (risk groups $4 \mathrm{a}$ and $4 \mathrm{~b}$ ). ${ }^{2}$ The patient characteristics of the patients with the median risk score in each of these five risk groups were used for the more detailed presentation of cost-effectiveness.

\section{Alternative scenarios}

Two alternative scenarios were investigated relating to the estimation of differential effectiveness. First, a pooled treatment effect was estimated from all randomised trials comparing early interventional and conservative strategies in NSTE-ACS. ${ }^{215-21}$ Data for this analysis were extracted from an earlier published meta-analysis ${ }^{1}$ updated with the results from the more recent ICTUS trial, ${ }^{17}$ the long-term results of FRISC II $^{18}$ and the RITA 3 analysis itself. In the second alternative scenario, an interaction between treatment effect and risk at randomisation was employed using the risk score defined in RITA $3 .^{2}$ Details of these analyses are available in the technical report (see supplementary report).

\section{Statistical analyses}

All statistical analyses were performed using Stata version 7 (Stata Statistical Software: Release 7.0. College Station, TX: Stata Corporation). The decision-analytic model was programmed and analysed in Microsoft ${ }^{\circledast}$ Excel (Microsoft Corporation, Redmond, Washington, USA).

\section{RESULTS}

\section{Clinical effectiveness}

The results of the analyses of effectiveness are summarised in table 1.

Although not significant, the early interventional strategy was associated with an increased risk of a composite endpoint (odds ratio 1.520) during the index hospitalisation. Age and severe angina were statistically significant risk factors associated with an increased risk of a composite endpoint.

After the index hospitalisation, the early interventional strategy was associated with a statistically significant lower rate of cardiovascular death or myocardial infarction (hazard ratio 0.621). All risk factors bar one (angina) were statistically significant; however, the hazard ratio for angina was close to significance and was retained in the model as a likelihood ratio test favoured the full model. The Weibull time-to-event model also showed that the rate of the composite endpoint declines as time elapses from hospital discharge.

The risk of a second composite endpoint of cardiovascular death or myocardial infarction was estimated to be about $50 \%$ higher than the risk of a first composite endpoint. The probability of a composite endpoint being non-fatal was higher in the index hospitalisation than during the follow-up period. For patients having suffered a myocardial infarction previous to the trial, a subsequent event was more likely to be fatal.

Table 1 Estimated short-term and long-term risks of the composite endpoint of cardiovascular death or myocardial infarction and the predicted proportion of composite events being non-fatal

\begin{tabular}{|c|c|c|c|c|c|c|c|c|c|}
\hline \multirow[b]{2}{*}{ Explanatory variables } & \multicolumn{3}{|c|}{$\begin{array}{l}\text { Odds ratio of composite endpoint of } \\
\text { myocardial infarction or cardiovascular } \\
\text { death during the index hospitalisation } \\
\text { (equation 1) } \\
\text { (n=1808) }\end{array}$} & \multicolumn{3}{|c|}{$\begin{array}{l}\text { Hazard ratio of composite endpoint of } \\
\text { myocardial infarction or cardiovascular } \\
\text { death from hospital discharge until end of } \\
\text { trial (equations } 2 \text { and } 3)^{*} \\
(n=1756)\end{array}$} & \multicolumn{3}{|c|}{$\begin{array}{l}\text { Odds ratio of composite endpoint being } \\
\text { non-fatal (equation } 4) \\
(n=261 \text { ) }\end{array}$} \\
\hline & Odds ratio & $\begin{array}{l}\text { 95\% lower } \\
\text { limit }\end{array}$ & $\begin{array}{l}\text { 95\% upper } \\
\text { limit }\end{array}$ & Hazard ratio & $\begin{array}{l}95 \% \text { lower } \\
\text { limit }\end{array}$ & $\begin{array}{l}\text { 95\% upper } \\
\text { limit }\end{array}$ & Odds ratio & $\begin{array}{l}\text { 95\% lower } \\
\text { limit }\end{array}$ & $\begin{array}{l}\text { 95\% upper } \\
\text { limit }\end{array}$ \\
\hline Age (for every 10 years over 60 ) & 1.731 & 1.262 & 2.374 & 1.777 & 1.499 & 2.108 & 0.699 & 0.520 & 0.941 \\
\hline Diabetes & & & & 1.905 & 1.359 & 2.672 & & & \\
\hline Previous myocardial infarction & & & & 1.471 & 1.087 & 1.990 & 0.492 & 0.286 & 0.847 \\
\hline Smoker & & & & 1.651 & 1.207 & 2.258 & & & \\
\hline Pulse (for every 5 beats per minute) & & & & 1.062 & 1.012 & 1.114 & & & \\
\hline ST depression & & & & 1.423 & 1.067 & 1.913 & & & \\
\hline Angina (grade 3 or 4 ) & 1.893 & 1.086 & 3.299 & 1.323 & 0.988 & 1.771 & & & \\
\hline Male & & & & 1.372 & 1.007 & 1.869 & & & \\
\hline Left bundle branch block & & & & 1.977 & 1.169 & 3.344 & & & \\
\hline $\begin{array}{l}\text { Randomised to early interventional } \\
\text { strategy }\end{array}$ & 1.520 & 0.864 & 2.675 & 0.621 & 0.464 & 0.830 & & & \\
\hline Ancillary parameter $\dagger$ & & & & 0.579 & 0.505 & 0.664 & & & \\
\hline $\begin{array}{l}\text { Composite endpoint during the index } \\
\text { hospitalisation }\end{array}$ & & & & & & & 3.040 & 1.614 & 5.726 \\
\hline
\end{tabular}


Table 2 Estimated costs during the index hospitalisation and the first year after the index hospitalisation

\begin{tabular}{|c|c|c|c|c|}
\hline \multirow[b]{2}{*}{ Explanatory variables } & \multicolumn{2}{|c|}{$\begin{array}{l}\text { Costs during the } \\
\text { index } \\
\text { hospitalisation } \\
\text { ( } n=1808 \text { ) }\end{array}$} & \multicolumn{2}{|c|}{$\begin{array}{l}\text { Costs first year after } \\
\text { the index } \\
\text { hospitalisation } \\
\text { ( } \mathrm{n}=1789 \text { ) }\end{array}$} \\
\hline & Cost & SE & Cost & SE \\
\hline Constant* & 1778 & 295 & 2735 & 248 \\
\hline Age (for every 10 years over 60 ) & 878 & 153 & & \\
\hline Previous myocardial infarction & & & 724 & 262 \\
\hline ST depression & 1224 & 268 & & \\
\hline Angina (grade 3 or 4 ) & & & 1034 & 247 \\
\hline Male & 1035 & 264 & 586 & 242 \\
\hline $\begin{array}{l}\text { Randomised to early interventional } \\
\text { strategy }\end{array}$ & 5654 & 256 & -1106 & 233 \\
\hline $\begin{array}{l}\text { Non-fatal myocardial infarction } \\
\text { during the index hospitalisation }\end{array}$ & 6221 & 972 & & \\
\hline $\begin{array}{l}\text { Dying during the index } \\
\text { hospitalisation }\end{array}$ & 7947 & 1229 & & \\
\hline Myocardial infarction during year & & & 5467 & 804 \\
\hline
\end{tabular}

* Cost of patients in the conservative arm without any of the risk factors included in the analyses and not suffering cardiovascular death or myocardial infarction. Other coefficients show the additional costs for each covariate.

$\mathrm{SE}$, standard error.

\section{Costs}

The results of the cost analyses are shown in table 2. During the index hospitalisation, the early interventional strategy was associated with a higher mean cost of $£ 5654$ compared with a conservative strategy. This was mainly the result of the higher number of angiographies and revascularisations in the early interventional arm. During the first year after the index hospitalisation, the early interventional strategy was associated with a lower mean cost of $£ 1106$ compared with the conservative strategy, reflecting the fact that more patients in the conservative strategy had further symptoms that necessitated revascularisation during this period. Patients had a substantially higher mean cost, irrespective of treatment

Table 3 Estimated $\mathrm{HROOL}$ (in terms of utilities) at randomisation and changes in $\mathrm{HROOL}$ from randomisation measured by the EQ-5D index

\begin{tabular}{|c|c|c|c|c|}
\hline \multirow[b]{2}{*}{ Explanatory variables } & \multicolumn{2}{|c|}{$\begin{array}{l}\text { Utility at } \\
\text { randomisation } \\
\text { ( } n=1799)\end{array}$} & \multicolumn{2}{|c|}{$\begin{array}{l}\text { Change in utility at } \\
\text { follow-up } \\
\text { ( } n=1734)\end{array}$} \\
\hline & Utility & SE & $\begin{array}{l}\text { Change in } \\
\text { utility }\end{array}$ & SE \\
\hline Constant* & 0.692 & 0.015 & & \\
\hline Diabetes & -0.051 & 0.021 & & \\
\hline Previous myocardial infarction & -0.044 & 0.016 & -0.010 & 0.016 \\
\hline ST depression & -0.066 & 0.015 & & \\
\hline Angina (grade 3 or 4 ) & -0.074 & 0.015 & & \\
\hline Male & 0.073 & 0.015 & & \\
\hline $\begin{array}{l}\text { Randomised to conservative strategy } \\
\text { (4-month follow-up) }\end{array}$ & & & 0.044 & 0.013 \\
\hline $\begin{array}{l}\text { Randomised to early interventional } \\
\text { strategy (4-month follow-up) } \dagger\end{array}$ & & & 0.038 & 0.017 \\
\hline $\begin{array}{l}\text { Randomised to conservative strategy } \\
\text { (12-month follow-up) }\end{array}$ & & & 0.038 & 0.008 \\
\hline $\begin{array}{l}\text { Randomised to early interventional } \\
\text { strategy (12-month follow-up) } \dagger\end{array}$ & & & 0.018 & 0.015 \\
\hline Myocardial infarction during year & & & -0.035 & 0.022 \\
\hline
\end{tabular}

*The constant shows the utility at randomisation for a patient without any of the risk factors included in the analyses. A negative (positive) sign indicates that the risk factor is associated with a lower (higher) utility at randomisation.

$\dagger$ Note that coefficients represent the gain in utility in the early interventional strategy over and above that of the conservative strategy.

$\mathrm{SE}$, standard error.

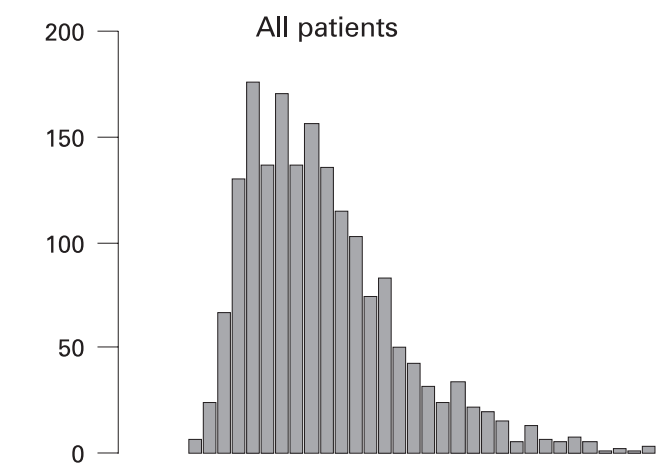

Risk group 1
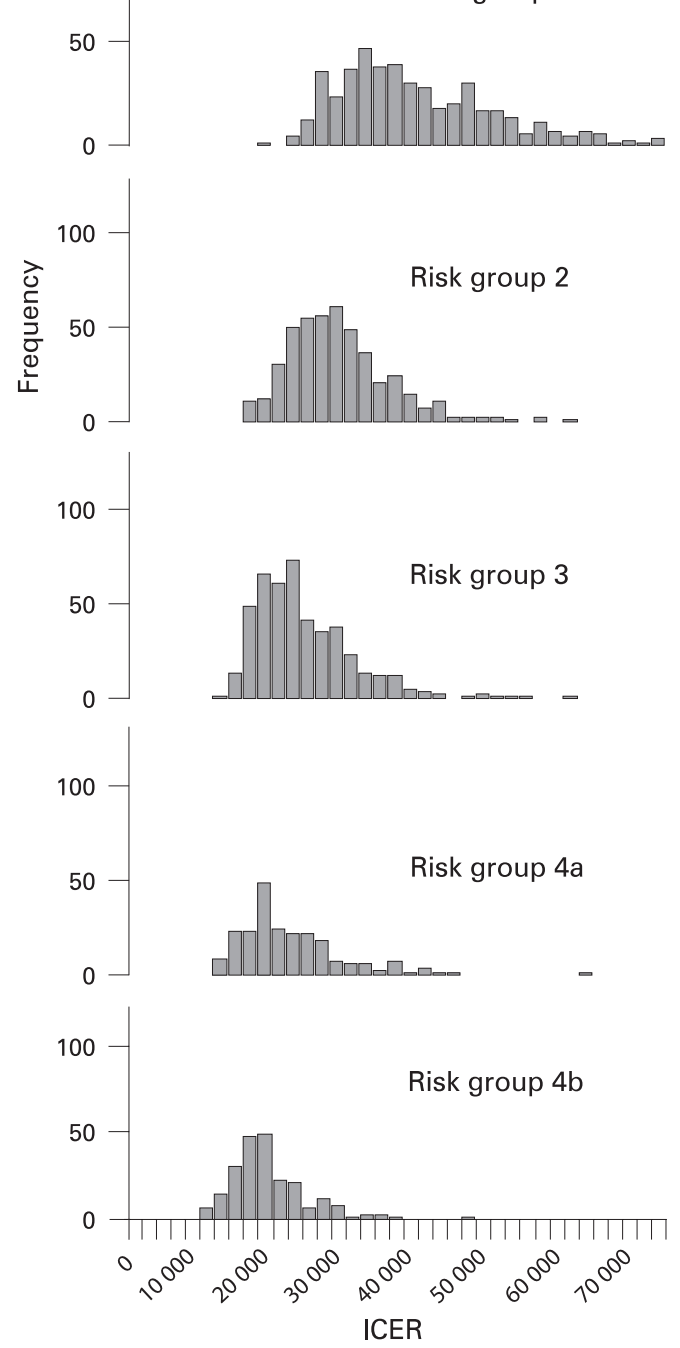

Figure 2 Cost-effectiveness based on estimated mean costs and OALYs, with and without early intervention, for patients in RITA 3 ( $n=1807)$. ICER, incremental cost-effectiveness ratio. Risk groups based on predicted risk of death or $\mathrm{MI}$ as defined in RITA $3 .^{2}$

allocation, if they suffered a myocardial infarction within the previous year or prior to the trial.

\section{Health-related quality of life}

The results of the analyses of HRQoL are presented in table 3 . At randomisation, mean $\mathrm{HRQOL}$ (in terms of utilities) was 
higher for males whereas diabetes, previous myocardial infarction, ST depression and angina were associated with lower HRQoL. In both treatment strategies HRQoL was improved at 4 months, although a greater improvement was seen with the early interventional strategy than with the conservative strategy. Between 4 and 12 months, HRQoL was improved further in both treatment strategies, although the additional gain of the early interventional strategy did not reach conventional levels of statistical significance. An MI during the study period was associated with lower HRQoL regardless of treatment allocation and a previous MI prior to study inclusion was associated with a small mean decrement in HRQoL.

\section{Cost-effectiveness}

\section{Base-case analysis}

The predicted mean cost-effectiveness for patients with the characteristics of each individual patient in RITA 3 is shown in fig 2, highlighting the substantial heterogeneity in mean costeffectiveness between patients with different risk profiles. Using a threshold of $£ 20000$ per OALY, an early interventional strategy is cost-effective for more patients in the higher-risk groups, although there is still substantial variation in costeffectiveness within these risk groups.

The cost-effectiveness results of five illustrative patients representing each risk group are shown in table 4 . The early interventional strategy has a favourable ICER and a high probability of being cost-effective for the patients in the fourth quartile of risk (both lower and upper risk halves of the quartile), and a high ICER with a low probability of being costeffective for the patient representing the first quartile of risk. For the patients representing the second and third quartiles of risk, the ICERs are below conventional threshold values for the UK.

\section{Alternative scenarios}

The estimated effectiveness and cost-effectiveness for the alternative scenarios are shown in table 5 for the same illustrative patients in each risk group. The pooled treatment effects from the meta-analysis of eight trials were similar to the treatment effect observed in RITA 3 (in both the index and follow-up periods). Hence the estimated cost-effectiveness using this alternative scenario is similar to that observed using data only from RITA 3.

The analysis in which the effectiveness of early intervention is permitted to vary according to patients' risk showed that a higher baseline risk was associated with an improved relative treatment effect, although this interaction was not statistically significant. Incorporating this interaction within the model improved the cost-effectiveness of an early interventional strategy in patients at high risk compared with the base-case scenario of a common treatment effect. Conversely, for patients at low risk, cost-effectiveness was much less favourable compared with the base-case scenario (table 5).

Details of the sensitivity scenarios are available in the technical report. The base-case results appeared robust to the assumptions required for the long-term extrapolation with the exception of the duration of the treatment effect of an early interventional strategy after the 5 years of trial follow-up. Extending the duration of the treatment effect beyond the 5 years observed in RITA 3 had an expected positive effect on cost-effectiveness and hence an early interventional strategy could be considered cost-effective in more patients under such scenarios.

\section{DISCUSSION}

The analysis shows that, in patients presenting with NSTE-ACS at high risk of further cardiac events, an early interventional strategy is associated with a gain in OALYs at an additional cost likely to be considered acceptable when compared with a conservative strategy. However, for patients at low risk, an early interventional strategy is associated with a high cost per OALY gained. For patients at intermediate risk, the cost per OALY gained is within generally accepted thresholds, so decisions about cost-effectiveness are likely to be finely balanced.

An important feature of the methods used in the analysis is that, as part of the scenario analysis, all available trial evidence was synthesised. This allowed evidence from seven trials (additional to RITA 3) to be reflected in the cost-effectiveness estimates. This re-estimation of the treatment effects had little effect on mean estimates of cost-effectiveness, but this analysis could be argued to more accurately reflect the uncertainty in the treatment effect parameters as all randomised evidence is taken into account.

Table 4 Cost-effectiveness results by patient risk profile

\begin{tabular}{|c|c|c|c|c|c|}
\hline & Risk group 1 & Risk group 2 & Risk group 3 & Risk group $4 a$ & Risk group $4 b$ \\
\hline Age & 45 & 52 & 52 & 61 & 66 \\
\hline Diabetes & No & No & No & No & Yes \\
\hline Previous myocardial infarction & No & No & Yes & Yes & Yes \\
\hline Smoker & No & Yes & No & Yes & No \\
\hline Pulse (beats per minute) & 72 & 82 & 82 & 87 & 97 \\
\hline ST depression & No & No & Yes & Yes & Yes \\
\hline Angina (grade 3 or 4 ) & Yes & No & Yes & No & No \\
\hline Sex & Female & Male & Male & Male & Male \\
\hline Left bundle branch block & No & No & No & No & No \\
\hline Incremental cost $(f)$ & 4885 & 4898 & 6045 & 6538 & 6530 \\
\hline Incremental OALY & 0.091 & 0.213 & 0.283 & 0.547 & 0.512 \\
\hline $\operatorname{ICER}(\mathrm{f})$ & 53760 & 22949 & 21325 & 11957 & 12750 \\
\hline $\begin{array}{l}\text { Probability early interventional strategy is cost-effective at } \\
£ 20000(£ 30000) \text { per } 0 A L Y^{*}\end{array}$ & $0.009(0.123)$ & $0.328(0.749)$ & $0.405(0.805)$ & $0.945(0.984)$ & $0.924(0.984)$ \\
\hline
\end{tabular}

Per OALY*

Illustrative patients based on predicted risk of death or MI as defined in RITA 3 represent each risk group.

* Proportion of simulations in the probabilistic analysis with an ICER below $£ 20000$ ( $£ 30000$ ).

ICER, incremental cost-effectiveness ratio; QALY, quality-adjusted life year. 


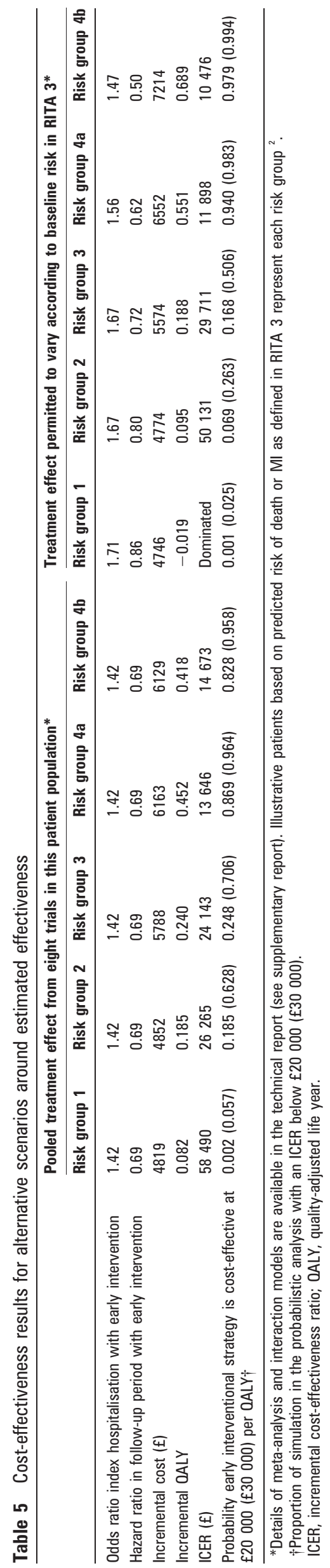

A key assumption in the base-case analysis is that the relative reduction in the risk of events conferred by an early interventional strategy is common across patients with different risk profiles. This is an assumption made in a number of costeffectiveness studies in the cardiac field. ${ }^{22}{ }^{23}$ Despite this assumption, the cost-effectiveness of early intervention varies according to patients' risk profile, as the latter determines their absolute benefit from early intervention which drives costeffectiveness. The appropriateness of the assumption of a common treatment effect across risk profiles has been questioned in the clinical analysis of RITA $3 .{ }^{2}$ This showed a clear beneficial treatment effect on the composite endpoint of death or MI of an early interventional strategy for patients in the upper risk half in the fourth quartile of risk, whereas in the first and second quartiles of risk the odds ratios were close to 1 . As part of the scenario analysis, an interaction between patients' baseline risks and the effectiveness of early intervention was incorporated into the cost-effectiveness model. This analysis reinforced the findings that an early interventional strategy is likely to be considered cost-effective in patients at high risk but not in patients at low risk. The conclusions were less clear for patients at intermediate risk, as early intervention was less costeffective under this scenario compared with the assumption of a common treatment effect.

It should be noted that the five illustrative patients for whom cost-effectiveness is reported in tables 4 and 5 merely represent an estimate of the mean cost-effectiveness of these risk groups. Within each risk group substantial variation can be observed, and therefore the results presented here by risk group should be seen as indicative. In deciding in which patients early intervention should be used, healthcare decision-makers will need to consider specific combinations of characteristics that affect patients' risks, or see baseline risk as a continuous measure rather than as categorical.

A number of previous studies have reported on the costeffectiveness of an early interventional strategy. The TACTICSTIMI 18 trial showed that the early interventional strategy was dominated by a conservative strategy in a 6-month within-trial analysis. ${ }^{24}$ In the long-term extrapolation, the cost per life-year gained varied between $\$ 9500$ (approximately $£ 5200,2000$ price level) and \$17 200 (£9500) using different assumptions of longterm treatment effect and different sources of long-term life expectancy. The FRISC II trial reported high incremental costs per prevented death or MI (649000 Swedish kronor (SEK) or approximately £48 000, 2000 price level) in a within-trial analysis of 1 year's duration. ${ }^{25}$ In a second economic evaluation from the FRISC II trial, data on costs and quality of life at 2 years' follow-up was available and extrapolated to a lifetime perspective. ${ }^{26}$ The reported cost per OALY was 55000 SEK (£4100, 2002 price level). Exploring cost-effectiveness in different subgroups did not alter the conclusions that an early interventional strategy is cost-effective.

In general, the results from these previous studies follow a similar trend to the findings in the present analysis, namely that an early interventional strategy does not appear cost-effective in the limited short-term perspective, whereas in the more relevant long-term perspective an early interventional strategy can yield positive health outcomes at an acceptable cost, at least in patients at high risk. In contrast to previous studies, the present analysis appears to demonstrate that risk stratification is likely to have a significant impact on the cost-effectiveness of an early interventional strategy.

Sensitivity scenarios indicated that the base-case results appeared robust to the assumptions employed for the 
long-term extrapolation, with the exception of the duration of the treatment effect after the 5-year follow-up from RITA 3. Extending the duration of the long-term treatment effect of an early interventional strategy beyond 5 years improved costeffectiveness. The extent to which this may change the decision regarding the adoption of an early interventional strategy will depend upon the strength of the decision-makers' beliefs about the duration of the treatment effect, and whether the treatment effect is considered to be constant or is likely to vary across different risk groups.

A limitation of the present study is that comprehensive data on costs was only collected up to 1 year after randomisation in RITA 3. However, the assumptions for the long-term extrapolation were conservative for the early interventional strategy. A further limitation is that individual-patient data was only available from RITA 3 for the present analysis. Future work should explore the impact of the results of employing individual-patient data from other relevant trials.

In conclusion, the results of the present analysis show that an early interventional strategy in patients presenting with NSTEACS appears cost-effective for patients at high and intermediate risk, but is unlikely to be so for patients at low risk.

Acknowledgements: We thank all the investigators and coordinators of the RITA 3 trial; the medical and nursing staff in the participating centres for recruitment and follow-up of patients; and, most of all, the patients who participated in the trial. We also thank Robbert deWinter for providing data from the ICTUS trial for the metaanalysis.

Funding: RITA 3 was funded by a competitive grant from the British Heart Foundation, and the British Heart Foundation received a donation from Aventis Pharma. Additional governmental support (Culyer) was obtained to reimburse interventional centres for part of the costs of $\mathrm{PCl}$ procedures. The analysis and preparation of the manuscript were undertaken independently of the funding sources.

Competing interests: None.

\section{REFERENCES}

1. Mehta SR, Cannon CP, Fox KA, et al. Routine vs selective invasive strategies in patients with acute coronary syndromes: a collaborative meta-analysis of randomized trials. JAMA 2005;293:2908-17.

2. Fox KA, Poole-Wilson P, Clayton TC, et al. 5-year outcome of an interventional strategy in non-ST-elevation acute coronary syndrome: the British Heart Foundation RITA 3 randomised trial. Lancet 2005;366:914-20.

3. Kim J, Henderson RA, Pocock SJ, et al. Health-related quality of life after interventional or conservative strategy in patients with unstable angina or non-STsegment elevation myocardial infarction: one-year results of the third Randomized Intervention Trial of unstable Angina (RITA-3). J Am Coll Cardiol 2005;45:221-8.

4. National Institute for Clinical Excellence (NICE). Guide to the Methods of Technology Appraisal. London: NICE, 2004.

5. Fox KA, Poole-Wilson PA, Henderson RA et al Interventional versus conservative treatment for patients with unstable angina or non-ST-elevation myocardial infarction: the British Heart Foundation RITA 3 randomised trial. Randomized Intervention Trial of unstable Angina. Lancet 2002;360:743-51.
6. Collet D. Modelling survival data in medical research. London: Chapman \& Hall, 1994:107-47.

7. Government Actuary Department. Interim life tables. Expectation of life for males in the United Kingdom, based on data for the years 2002-2004. http:// www.gad.gov.uk (accessed 21 0ct 2006).

8. National Statistics. Review of the registrar general on deaths by cause, sex and age, in England and Wales. London: National Statistics, 2003.

9. Epstein DM, Sculpher MJ, Clayton TC, et al. Costs of an early intervention versus a conservative strategy in acute coronary syndrome. Int J Cardiol. Published Online First: 17 August 2007.

10. Brooks R. EuroQol: the current state of play. Health Policy 1996;37:53-72.

11. Dolan P. Modeling valuations for EuroOol health states. Medical Care 1997;35:1095-108.

12. Karlsson G, Johannesson M. The decision rules of cost-effectiveness analysis. Pharmacoeconomics 1996:9:113-20.

13. Claxton K. The irrelevance of inference: a decision-making approach to the stochastic evaluation of health care technologies. J Health Econ 1999:18:341-64.

14. Claxton K, Sculpher M, Drummond M. A rational framework for decision making by the National Institute For Clinical Excellence (NICE). Lancet 2002;360:711-5.

15. Spacek R, Widimsky $\mathrm{P}$, Straka Z, et al. Value of first day angiography/angioplasty in evolving Non-ST segment elevation myocardial infarction: an open multicenter randomized trial. The VINO Study. Eur Heart J 2002;23:230-8.

16. Anderson HV, Cannon $\mathrm{CP}$, Stone $\mathrm{PH}$, et al. One-year results of the Thrombolysis in Myocardial Infarction (TIMI) IIIB clinical trial. A randomized comparison of tissue-type plasminogen activator versus placebo and early invasive versus early conservative strategies in unstable angina and non-0 wave myocardial infarction. J Am Coll Cardiol 1995;26:1643-50.

17. de Winter RJ, Windhausen F, Cornel JH, et al. Early invasive versus selectively invasive management for acute coronary syndromes. N Engl J Med 2005;353:1095104.

18. Lagerqvist B, Husted S, Kontny F, et al. 5-year outcomes in the FRISC-II randomised trial of an invasive versus a non-invasive strategy in non-ST-elevation acute coronary syndrome: a follow-up study. Lancet 2006;368:998-1004.

19. Boden WE, O'Rourke RA, Crawford MH, et al. Outcomes in patients with acute nonQ-wave myocardial infarction randomly assigned to an invasive as compared with a conservative management strategy. Veterans Affairs Non-Q-Wave Infarction Strategies in Hospital (VANOWISH) Trial Investigators. N Engl J Med 1998;338:1785-92

20. McCullough PA, O'Neill WW, Graham M, et al. A prospective randomized trial of triage angiography in acute coronary syndromes ineligible for thrombolytic therapy. Results of the medicine versus angiography in thrombolytic exclusion (MATE) trial. J Am Coll Cardiol 1998;32:596-605.

21. Cannon CP, Weintraub WS, Demopoulos LA, et al. Comparison of early invasive and conservative strategies in patients with unstable coronary syndromes treated with the glycoprotein Ilb/lla inhibitor tirofiban. N Engl J Med 2001;344:1879-87.

22. Briggs A, Mihaylova B, Sculpher M, et al. Cost-effectiveness of perindopril in reducing cardiovascular events in patients with stable coronary artery disease using data from the EUROPA Study. Heart 2007;93:1015-6.

23. Heart Protection Study Collaborative Group. Lifetime cost effectiveness of simvastatin in a range of risk groups and age groups derived from a randomised trial of 20,536 people. BMJ 2006;333:1145-8

24. Mahoney EM, Jurkovitz CT, Chu H, et al. Cost and cost-effectiveness of an early invasive vs conservative strategy for the treatment of unstable angina and non-STsegment elevation myocardial infarction. JAMA 2002;288:1851-8.

25. Janzon M, Levin LA, Swahn E. Cost-effectiveness of an invasive strategy in unstable coronary artery disease; results from the FRISC II invasive trial. The Fast Revascularisation during InStability in Coronary artery disease. Eur Heart $J$ 2002:23:31-40.

26. Janzon M. Treatment strategies in unstable coronary artery disease, economic and quality of life evaluations [dissertation]. Medical dissertation No. 811: Linköping University, 2003:1-176. 